\title{
Partículas ambientales en bronquio y tejido pulmonar humano
}

\section{Environmental particles in bronchus and human lung tissue}

\author{
PEÑA-GARCIA, Laura †े, MACIEL-FLORES, Roberto, ROBLES-MURGUÍA, Celia y ROSAS- \\ ELGUERA, José
}

Universidad de Guadalajara. Centro Universitario de Ciencias Biológicas y Agropecuarias. Camino Ramón Padilla Sánchez 2100, Nextipac, 44600 Zapopan, Jal.

ID $1^{\text {er }}$ Autor: Laura, Peña-García / ORC ID: 0000-0002-9008-133, Researcher ID Thomson: U-4752-2018, CVU CONACYT ID: 311129

ID $1^{\text {er }}$ Coautor: Roberto, Maciel-Flores / ORC ID: 0000-0002-3540-860X

ID $2^{\text {do }}$ Coautor: Celia, Robles-Murgía / ORC ID: 0000-0001-6413-0478, SCOPUS ID: 22948975000

ID $3^{\text {er }}$ Coautor: Diana Luz, Torres-Bárcenas / CVU CONACYT ID: 10786

DOI: $10.35429 /$ JOHS.2019.18.6.10.17

Recibido Enero 09, 2019; Aceptado Marzo 15, 2019

\begin{abstract}
Resumen
Objetivo. Identificar partículas ambientales en bronquio y tejido pulmonar humano por medio de la técnica SEM. Metodología Las muestras se fijaron por inmersión en glutaraldehído al $2 \%$ durante 2 horas, posteriormente se realizó un lavado con amortiguador de fosfatos $1 \mathrm{x} \mathrm{pH} 7$ y ligera agitación (x3) (1x, 2x y x3). Finalmente, las muestras se desecaron de punto crítico con un equipo Samdri 795 de Tousimis. Este fue el proceso al que se llevaron las muestras para realizar análisis EDS con un equipo Jeol JSM 6610LV, operándose a $10 \mathrm{kV}$, con detector EDS Oxford Xmax y software AZtec de Oxford. La observación en el microscopio electrónico de barrido se realizó con detector de electrones secundarios. Para el montaje se utilizó un porta muestras para microscopia electrónica de barrido, sobre un sustrato de cinta doble cara de carbón. Se les dio a las muestras un recubrimiento con material conductor (oro 99.9\%) mediante sputtering con el equipo Denton Vacuum V. Contribución. En pulmón se identificaron 21 elementos, además de observar la forma y tamaño de las partículas. Dichas imágenes se compararon con algunas otras partículas medioambientales presentadas por autores diversos. Se consultaron los usos de estos elementos y se identificó que algunos de ellos se utilizan en la industria automotriz, eléctrica y en medicina, además de que en la alimentación también tienen gran influencia.
\end{abstract}

Tejido pulmonar, SEM, Metales pesados

\begin{abstract}
Objectives. Identify environmental particles in bronchus and human lung tissue through the SEM technique Methodology. The samples were fixed by immersion in $2 \%$ glutaraldehyde for 2 hours, then a wash with $1 \mathrm{x} \mathrm{pH} 7$ phosphate buffer and light agitation (x3) (1x, 2x and $\mathrm{x} 3$ ) was performed. Finally, the samples were critically dried out with a Samdri 795 team from Tousimis. This was the process to which the samples were taken for EDS analysis with a Jeol JSM 6610LV equipment, operating at $10 \mathrm{kV}$, with Oxford Xmax EDS detector and Oxford AZtec software. The observation in the scanning electron microscope was performed with secondary electron detector. For the assembly, a sample holder was used for scanning electron microscopy, on a double-sided carbon tape substrate. The samples were given a coating with conductive material ( $99.9 \%$ gold) by sputtering with the Denton Vacuum V equipment. Contribution. In lung, 21 elements were identified, in addition to observing the shape and size of the particles. These images were compared with some other environmental particles presented by diverse authors. The uses of these elements were consulted and it was identified that some of them are used in the automotive, electrical and medical industries, and they also have a great influence on food.
\end{abstract}

Pulmonary tissue, SEM, Heavy metals

Citación: PEÑA-GARCIA, Laura, MACIEL-FLORES, Roberto, ROBLES-MURGUÍA, Celia y ROSAS-ELGUERA, José. Partículas ambientales en bronquio y tejido pulmonar humano. Revista de Ciencias de la Salud. 2019. 6-18: 10-17.

\footnotetext{
$\dagger$ Investigador contribuyendo como primer Autor
} 


\section{Introducción}

Los contaminantes más comunes del aire son partículas en suspensión entre cuyos componentes se encuentran metales pesados, nitratos y sulfatos, entre otros (Perez et al., 2006; Flores et al., 2013).

Las PM también conocidas como material particulado (por sus siglas en inglés particulate matter) están constituidas por la mezcla de compuestos químicos en forma de líquidos y sólidos suspendidos en el aire como hollín, polvo, humo y neblinas (Green et al., 2012). La contaminación del aire incluye "partículas gruesas inhalables", con diámetros de $2.5 \mu \mathrm{m}$, hasta $10 \mu \mathrm{m}$, "partículas finas", con diámetros menores a $2.5 \mu \mathrm{m}$ y "partículas ultrafinas" que se refieren a las partículas menores a $0.1 \mu \mathrm{m}$ (Secretaría de Medio Ambiente y Recursos Naturales, 2011; United States Environmental Protection Agency, 2015, 2016). Las principales características de estas partículas se resumen en el (Tabla 1).

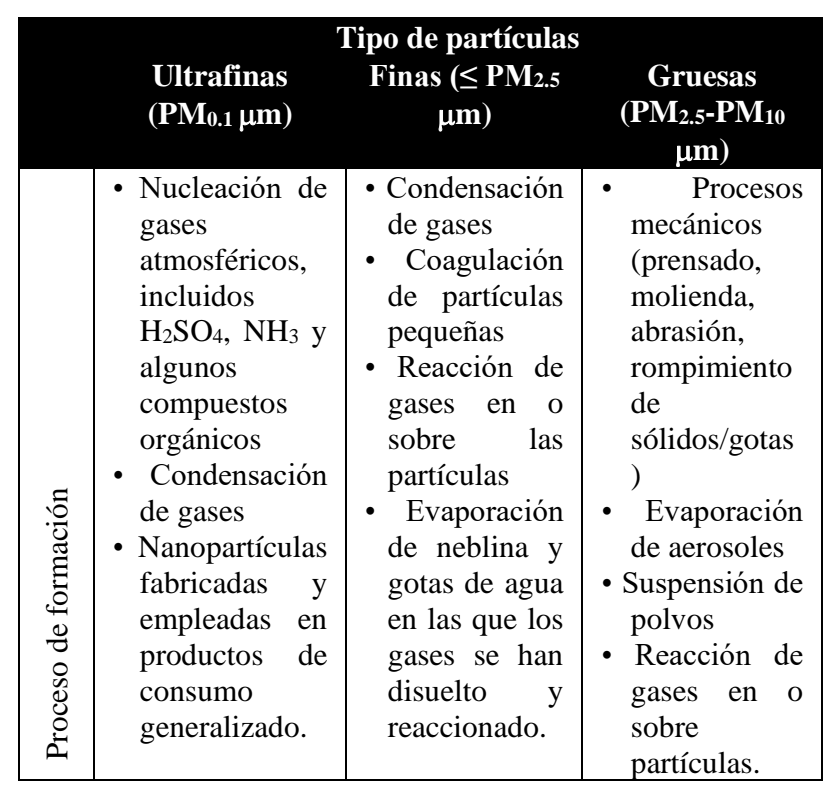

Tabla 1 Principales características de las partículas ultrafinas, finas y gruesas

Fuente: (Secretaría de Medio Ambiente y Recursos Naturales, 2011)

En general, las causas de la contaminación del aire pueden ser naturales (emisiones volcánicas, biogénicas, desérticas, marinas, etc.) o antropogénicas. Estas últimas son las que principalmente inciden de manera mayormente adversa sobre la calidad del aire (Querol, 2008).

\section{Afectaciones en la salud}

La contaminación del aire por partículas se ha asociado a diversos efectos, agudos y crónicos, en enfermedades respiratorias y cardiovasculares, dadas la diversidad en composición química y tamaños. Sin embargo, los problemas de salud que pueden generar las partículas ultrafinas (de un diámetro menor a $100 \mathrm{~nm}$ ) son evidentemente diferentes a los que se pueden presentar por las $\mathrm{PM}_{10}$ (Frejo, Díaz, Lobo, García, \& Capó, 2011). De hecho, las partículas ultrafinas, dependiendo de su tamaño, forma y composición química, son capaces de penetrar y depositarse en los diferentes compartimentos del aparato respiratorio, en la región extra-torácica incluyendo la boca, fosas nasales, laringe y faringe en la región traqueobronquial, de la tráquea a los bronquios y en la región alveolar que comprende los bronquíolos y los alvéolos (Figura 1) (Castañeda-Miranda, 2016; Frejo et al., 2011; Utell, 2002). Las partículas ultrafinas superiores a $10 \mathrm{~nm}$ se depositan principalmente en la región alveolar y las inferiores a $10 \mathrm{~nm}$ se depositan principalmente en la región extra torácica y en una menor cantidad en la región traqueo bronquial (Rosell et al., 2008; Aydin et al., 2012; Hoet et al., 2004).

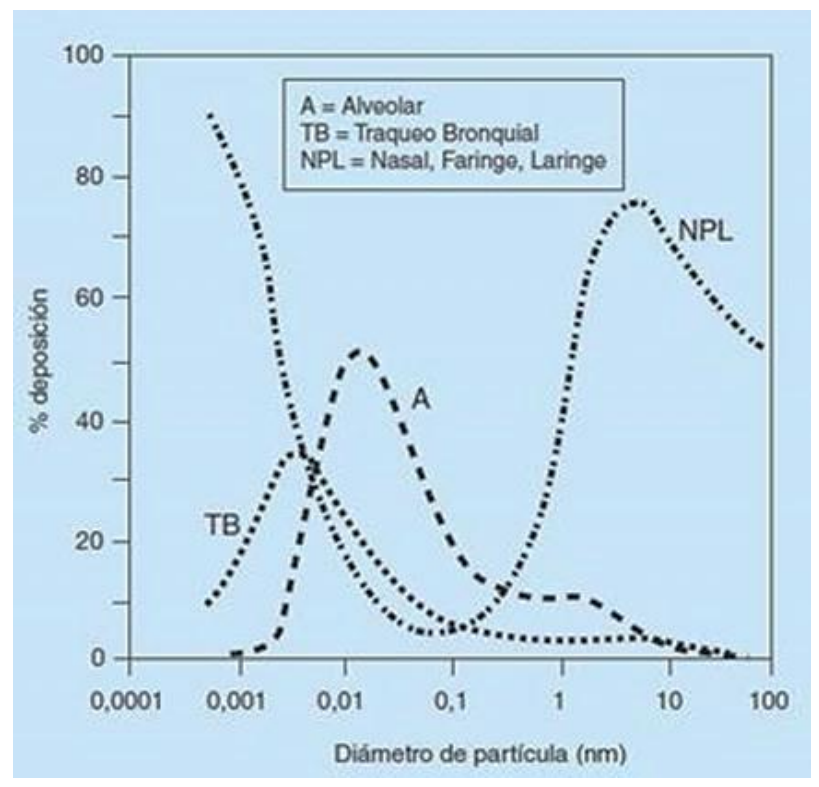

Figura 1 Porcentaje de deposición de partículas ultrafinas en función de su tamaño

Fuente: (Utell, 2002)

Se estima que $1 \%$ o menos de las NPs depositadas en los pulmones pasan a la circulación sistémica y a otros órganos. 
El aumento de la producción y el uso de las NPs $(<100 \mathrm{~nm})$ en diversos productos de consumo (pinturas, protectores solares y cosméticos), nano-medicamentos y diagnósticos, ha elevado el riesgo de exposición a este tipo de partículas (International Agency for Research on Cancer, 2012).

Existen otros tipos de partículas que se definen como fibras o material sólido con una relación de longitud/diámetro de al menos 3/1. La penetración en pulmón dependerá de sus propiedades aerodinámicas. Si las fibras son pequeñas penetrarán más profundamente en los pulmones, pero si son muy largas (> 20 micras) quedarán atrapadas en vías respiratorias superiores. El mecanismo de limpieza que tienen las vías respiratorias son los macrófagos, los cuales fagocitan las partículas extrañas o ajenas al pulmón, además de los cilios y el moco, los cuales facilitan la expulsión del material sólido a la boca. En cuanto a las fibras, si éstas son más grandes que los macrófagos, se eliminarán muy lentamente. En el caso de las fibras, que son inhaladas y que aparecen de manera constante en los alvéolos pulmonares, a menudo se pueden encontrar entre o dentro de las células que componen las paredes alveolares. Los materiales sólidos de tamaño nanométrico llegan fácilmente hasta los alvéolos y, en ocasiones, no alcanzan a ser eliminados por los procesos naturales de limpieza de los pulmones, dado que probablemente, la cantidad de material que ingresa es mayor que la capacidad de limpieza del organismo (Jia et al., 2010).

El objetivo del presente trabajo fue identificar partículas ambientales en bronquio y tejido pulmonar humano por medio de la técnica SEM.

\section{Metodología}

Se solicitó al Instituto Jalisciense de Ciencias Forenses (IJCF) la facilidad para observar mediante la técnica SEM muestras de bronquios principales, primeras ramificaciones o alveolos pulmonares para buscar la presencia de partículas. Dichas muestras pertenecieron a individuos hallados en los municipios que conforman el área metropolitana de Guadalajara. Las muestras se encontraban almacenadas en sus instalaciones y fueron preservadas en glutaraldehído al 2\% en tubos Eppendorf de 1.5 $\mathrm{ml}$.
La cantidad de muestra disponible era de medio centímetro cuadrado. Los ejemplares observados correspondían a individuos que no habían presentado lesiones en tórax y con bajo grado de descomposición. Todas las muestras observadas, un total de 12, correspondieron a individuos fallecidos en el año 2014. El objetivo de este análisis fue verificar si el tipo de partículas presentes en tejido pulmonar humano es similar a las partículas observadas por contaminación del aire.

\section{Metodología para procesar tejidos humanos}

Las muestras se fijaron por inmersión en glutaraldehído al $2 \%$ durante 2 horas, posteriormente se realizó un lavado con amortiguador de fosfatos $1 \mathrm{x} \mathrm{pH} 7$ y ligera agitación (x3) (1x, 2x y x3 se refiere al número de veces que se repitió el mismo paso).

A continuación, se aplicaron procesos de deshidratación con etanoles seriados:

$\begin{array}{lll}\text { 1. } & * \text { Etanol } 40 \% & 1 \text { hora } \\ \text { 2. } & * \text { Etanol } 50 \% & 1 \text { hora } \\ \text { 3. } & * \text { Etanol } 60 \% & 1 \text { hora } \\ \text { 4. } & * \text { Etanol } 70 \% & 1 \text { hora } \\ \text { 5. } & * \text { Etanol } 80 \% & 1 \text { hora } \\ \text { 6. } & * \text { Etanol } 90 \% & 1 \text { hora } \\ \text { 7. } & * \text { Etanol } 100 \% & 1 \text { hora }(2 \mathrm{x})\end{array}$

Finalmente, las muestras se desecaron de punto crítico con un equipo Samdri 795 de Tousimis. Este fue el proceso al que se llevaron las muestras para realizar análisis EDS con un equipo Jeol JSM 6610LV, operándose a 10kV, con detector EDS Oxford Xmax y software AZtec de Oxford. La observación en el microscopio electrónico de barrido se realizó con detector de electrones secundarios. Para el montaje se utilizó un porta muestras para microscopia electrónica de barrido, sobre un sustrato de cinta doble cara de carbón. Se les dio a las muestras un recubrimiento con material conductor (oro 99.9\%) mediante sputtering con el equipo Denton Vacuum V.

\section{Resultados}

A continuación, se informa la correlación que entre las partículas contaminantes identificadas en las muestras ambientales y las partículas que se encontraron en tejido pulmonar humano mediante la técnica SEM, para advertir sobre posibles riesgos en la salud de las personas. 
No obstante, son muy pocos los trabajos efectuados sobre los efectos tóxicos de partículas en estructuras celulares humanas (Paur et al., 2011). Las principales células sanguíneas observadas en las muestras que analizamos fueron eritrocitos, leucocitos (Figura 2), macrófagos y plaquetas. Los eritrocitos son las células sanguíneas más abundantes en la sangre; tienen forma de discos bicóncavos, su diámetro es entre 6 y $8 \mu \mathrm{m}$, el grosor es de $2 \mu \mathrm{m}$ (Jaime $e t$ al., 2009). Los leucocitos son un conjunto de células que desempeñan diversas funciones, todas relacionadas con la defensa del organismo frente a las infecciones y a la presencia de sustancias ajenas. Son células grandes que se clasifican en granulocitos, linfocitos y monocitos. Los monocitos son células grandes de 15 a $20 \mu \mathrm{m}$ de diámetro. Estas células viajan por la sangre y llegan al tejido conectivo, donde se convierten en macrófagos (González de Buitrago, 2010). Las plaquetas son discos finos de 2 a $4 \mu \mathrm{m}$ de diámetro. Participan en la homeostasis, en el mantenimiento de la integridad vascular $\mathrm{y}$ en el proceso de coagulación de la sangre (Conny et al., 2011).

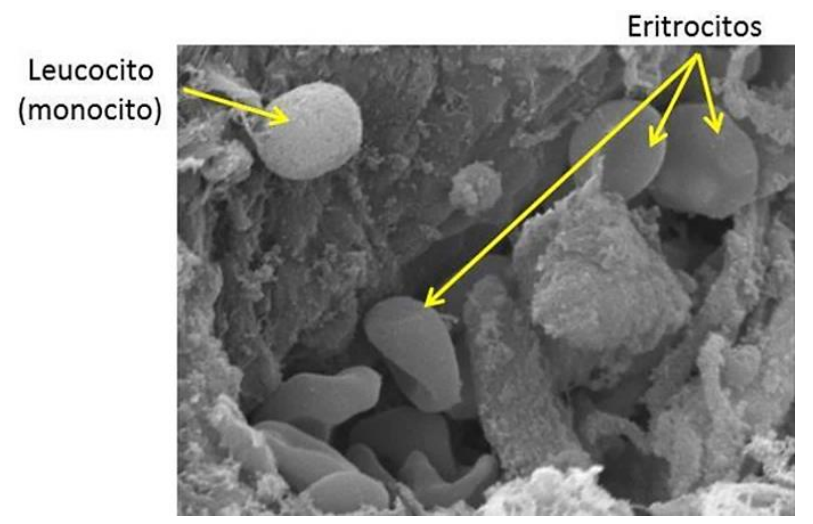

Figura 2 Eritrocitos, leucocitos

Las muestras que tuvieron mayor número de elementos fueron los individuos 1 y 9 con 12 elementos, con 10 elementos fueron los individuos 4 y 11 , posteriormente el 3 y 12 con 9 elementos, los individuos 5 y 6 presentaron 8 elementos cada uno, el 2 tuvo 7 elementos, el 7 y 10 cinco elementos. Los elementos más abundantes fueron $\mathrm{Al}, \mathrm{Pb}, \mathrm{As}, \mathrm{Hg}$ y W. Los menos abundantes fueron $\mathrm{Zn}$, Ta, Nb, Hf, $\mathrm{Cu}$ y $\mathrm{Rh}$. Los óxidos de osmio y compuestos de cromo pueden provocar congestión pulmonar y cáncer, respectivamente. El Re fue identificado en tejido pulmonar de tres individuos. Otros metales como $\mathrm{Rh}$ y $\mathrm{Pt}$, los cuales son componentes fundamentales de convertidores catalíticos de los autos, también fueron identificados en tejido pulmonar y son potencialmente cancerígenos.
Es especialmente interesante la identificación del elemento metálico plata en cuatro individuos, cuya fuente de emisión puede ser antropogénica o natural.

En Tabla 2 se describen las características observadas de manera general en las muestras de tejido pulmonar obtenidas $\mathrm{y}$ algunos detalles que se lograron identificar en algunos casos, como el tipo de exposición o posible actividad laboral que desarrollaron $y$ estado de salud de la persona. En todos los casos se observó algún tipo de partículas ajenas a pulmón. Hay que recordar que Yu et al., (2007) en su estudio identificó que las NPs tienden a tardar aproximadamente 15 días en acumularse en tejido pulmonar y Kreyling et al., (2011) también refiere que nano-agregados de $\mathrm{Ag}$ tienen la capacidad de mantenerse en la región intratraqueal por siete días y aquellas NPs puras viajan rápidamente a otros órganos. Se encontró que cuatro de los individuos tuvieron presencia de Ag en las regiones observadas.

A continuación (Tabla 2), se presentan las imágenes obtenidas de las muestras analizadas, en ellas se observa detalladamente el tejido pulmonar, así como sus estructuras. En las imágenes obtenidas de las muestras observadas en SEM se identifican estructuras anatómicas, células sanguíneas, así como cuerpos extraños o ajenos al tejido pulmonar.

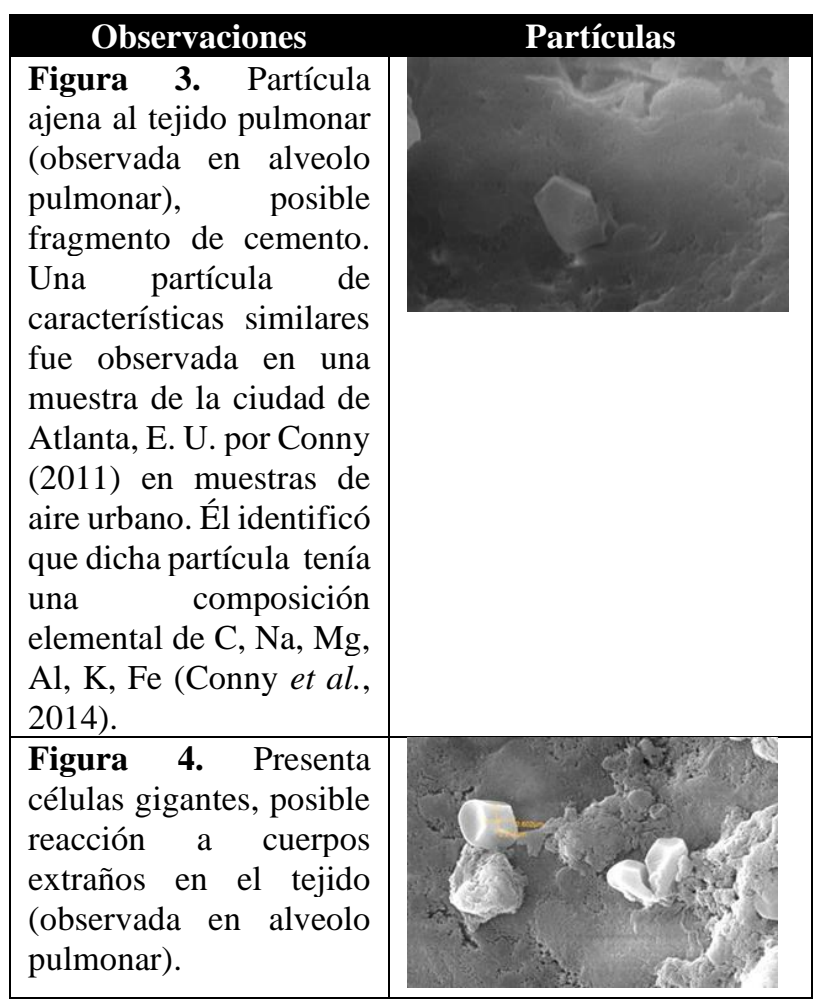




\begin{tabular}{|c|c|}
\hline $\begin{array}{l}\text { Figura 5. Fragmento de } \\
\text { algún mineral o de } \\
\text { material plástico, mismo } \\
\text { que en ocasiones se ha } \\
\text { encontrado en estómago } \\
\text { (observada en alveolo } \\
\text { pulmonar). }\end{array}$ & 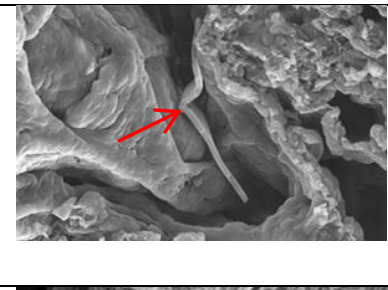 \\
\hline $\begin{array}{l}\text { Figura } 6 \text {. Grano de polen } \\
\text { y fragmentos de fibras } \\
\text { (sobre tejido conjuntivo } \\
\text { y colágena). }\end{array}$ & \\
\hline $\begin{array}{l}\text { Figura } 7 . \text { El individuo } \\
\text { pudo haber estado } \\
\text { asociado a actividades } \\
\text { eléctricas, como focos } \\
\text { ahorradores, empaque o } \\
\text { desecho de los mismos; } \\
\text { se dedujo por el } \\
\text { contenido de Hg en la } \\
\text { muestra. } \\
\text { Partículas raras } \\
\text { (observada sobre } \\
\text { alveolo pulmonar). }\end{array}$ & \\
\hline $\begin{array}{l}\text { Figura 8. Partícula ajena } \\
\text { a tejido pulmonar } \\
\text { (observada dentro } \\
\text { alveolo pulmonar), con } \\
\text { características de } \\
\text { partícula atmosférica, } \\
\text { similar a la partícula } \\
\text { observada en una } \\
\text { muestra colectada } \\
\text { cercana al centro de la } \\
\text { ciudad de Los Ángeles, } \\
\text { E. U. por Conny et al., } \\
\text { (2014), tomada en filtros } \\
\text { de fibra de cuarzo } \\
\text { purificados por calor en } \\
\text { un impactador virtual } \\
\text { dicotómico (Conny et } \\
\text { al., 2011), }\end{array}$ & \\
\hline $\begin{array}{lr}\text { Figura } 9 . & \text { Posible } \\
\text { individuo } & \text { con } \\
\text { inmunosupresión } \\
\text { importante o } \\
\text { Tejido muy deteriorado, } \\
\text { con } & \text { proceso } \\
\text { inflamatorio } & \\
\text { significativo. }\end{array}$ & \\
\hline $\begin{array}{l}\text { Pudo haber estado } \\
\text { asociado a adicciones } \\
\text { por inhalación de alguna } \\
\text { droga o también el } \\
\text { individuo pudo ser } \\
\text { fumador. } \\
\text { Se observó levadura, } \\
\text { posible moniliasis por } \\
\text { Candida (observada } \\
\begin{array}{ll}\text { dentro alveolo } \\
\text { pulmonar). }\end{array}\end{array}$ & \\
\hline
\end{tabular}

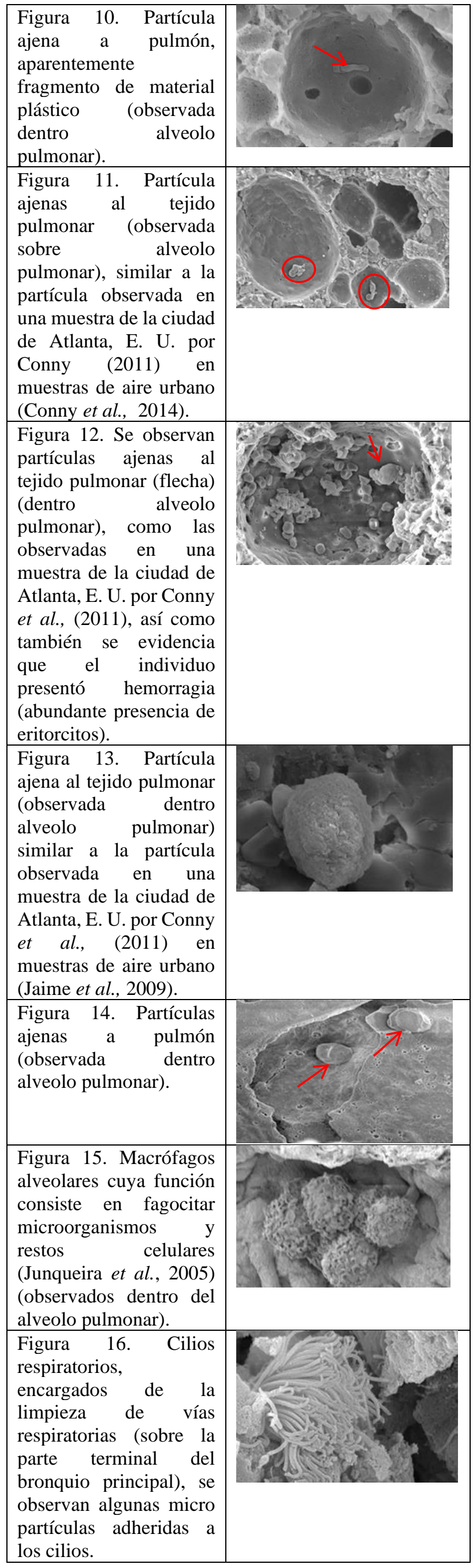

PEÑA-GARCIA, Laura, MACIEL-FLORES, Roberto, ROBLES-MURGUÍA, Celia y ROSAS-ELGUERA, José. Partículas ambientales en bronquio y tejido pulmonar humano. Revista de Ciencias de la Salud. 2019 


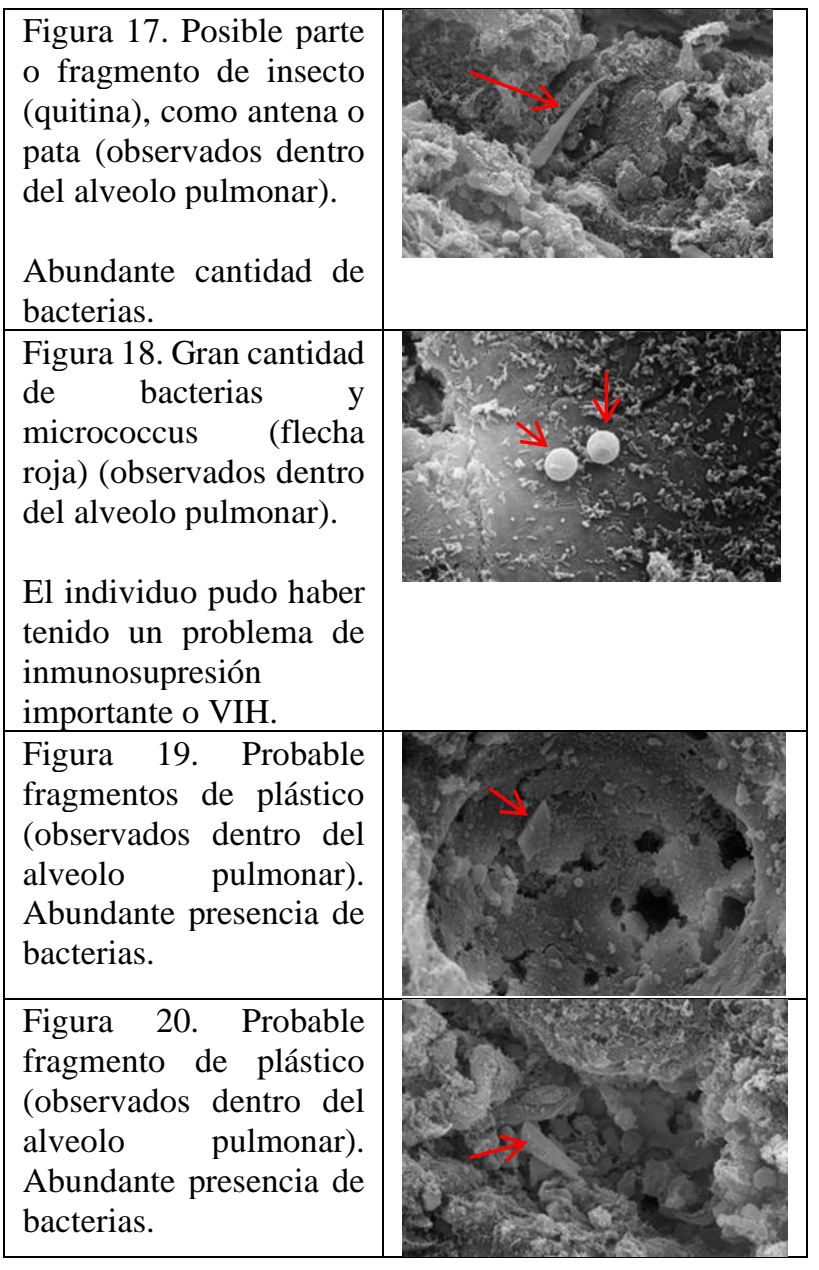

\section{Agradecimiento}

El presente proyecto recibió apoyo económico por parte de PROMEP, ya que, como cuerpo académico, nos invitó a participar en un macro proyecto de Redes titulado "Aplicación de la modelación numérica de macro y microescala para el diagnóstico y la predicción del transporte y dispersión de contaminantes en ciudades con altos índices de polución". El nombre de la red fue: Estudios de Impacto del Medio Ambiente, y fue promovida por el Cuerpo Académico UDGCA-423 Geociencias Ambientales Aplicadas de la Universidad de Guadalajara.

Al Lic. Carlos Daniel Barba Rodríguez, a la MC. Martha Claudia Gutiérrez Jiménez, al Dr. Mario Rivas Souza, al Ing. J. Jesús Francisco Durán Juárez y a la Dra. Angélica Ceceña del Instituto Jalisciense Forense (RENIECYT 2016/23661) por haber colaborado con el doctorado en Ciencias Físico Matemáticas de la Universidad de Guadalajara y por las facilidades para la observación de muestras de pulmón.

Muy especialmente al Dr. Alfredo Ignacio Feria y Velasco (†) (Investigador Nacional Emérito, CUCBA), por su invaluable apoyo.
De igual manera la Dra. Ruth Araceli De Celis Carrillo (Centro de Investigación Biomédica de Occidente), así como a la MC Rosa María Domínguez Arias y a la Dra. Josefina Casas Solís, ambas del Departamento de Biología Celular y Molecular. A la Médica General Cecilia Alhelí Cuellar Lemus por su constante respaldo, amistad y cariño.

\section{Conclusiones}

En pulmón se identificaron 21 elementos, además de observar la forma y tamaño de las partículas. Dichas imágenes se compararon con algunas otras partículas medioambientales presentadas por autores diversos. Se consultaron los usos de estos elementos y se identificó que algunos de ellos se utilizan en la industria automotriz, eléctrica y en medicina, además de que en la alimentación también tienen gran influencia. Se demostró que las partículas ambientales son capaces de pasar las barreras naturales del cuerpo y llegar a sitios muy distantes siendo su tamaño fundamental para que esto suceda: mientras más finas van a viajar más lejos tanto dentro como fuera del organismo.

\section{Referencias}

Aydın, A., Sipahi, H., \& Charehsaz, M. (2012). Nanoparticles toxicity and their routes of exposures.

Castañeda-Miranda, A. G. (2016). Caracterización y monitoreo magnéticoambiental de partículas suspendidas del aire urbano. Universidad Nacional Autónoma de México. Retrieved from http://terra.geociencias.unam.mx/geociencias/p osgrado/tesis/doctorado/castaneda_miranda_ag. pdf

Conny, J. M., Collins, S. M., \& Herzing, A. A. (2014). Qualitative multiplatform microanalysis of individual heterogeneous atmospheric particles from high-volume air samples. Analytical Chemistry, 86(19), 9709-9716. https://doi.org/10.1021/ac5022612

Conny, J. M., \& Norris, G. A. (2011). Scanning electron microanalysis and analytical challenges of mapping elements in Urban atmospheric particles. Environmental Science and Technology, 45(17), 7380-7386. https://doi.org/10.1021/es2009049 
Flores, J., Vaca, M., López, R., González, A., Hachec, R., \& Hernández, M. (2013). Evaluación de la movilidad de plomo y zinc en depósitos secos atmósfericos en el norte de la ciudad de México. Journal of Chemical Information and Modeling, 53(9), 1689-1699. https://doi.org/10.1017/CBO9781107415324.00 4

Frejo, M. T., Díaz, M. J., Lobo, M., García, J., \& Capó, M. (2011). Nanotoxicología ambiental: retos actuales. Medicina Balear, 26(2), 36-46. Retrieved from http://www.medicinabalear.org/pdfs/Vol26n2.p df

González de Buitrago, J. M. (2010). Técnicas y métodos de laboratorio clínico (3a edición). Barcelona: Elsevier Masson.

Green, J., \& Sánchez, S. (2012). La Calidad del Aire en América Latina: Una Visión Panorámica, 36. Retrieved from http://www.cleanairinstitute.org/calidaddelairea mericalatina/cai-report-spanish.pdf

Hoet, P. H., Brüske-Hohlfeld, I., \& Salata, O. V. (2004). Nanoparticles - known and unknown health risks. Journal of Nanobiotechnology, 2, 12. https://doi.org/10.1186/1477-3155-2-12

International Agency for Research on Cancer. (2012). Occupational exposure as a painter. IARC Monographs on the Evaluation of Carcinogenic Risks to Humans, 100 F. Retrieved from

http://monographs.iarc.fr/ENG/Monographs/vol 98/mono98-6A.pdf

Jaime, J. C., \& Gómez, D. (2009). Hematología. La sangre y sus enfermedades (Segunda ed). México, D. F.: McGraw Hill.

Jia, J., Muralikrishnan, S., Ng, C., Yung, L. L., \& Bay, B. (2010). Minireview Nanoparticleinduced pulmonary toxicity. Experimental Biology and Medicine, 235(1535-3702), 10251033. Retrieved from http://journals.sagepub.com/doi/pdf/10.1258/eb m.2010.010021

Junqueira, L., \& Carneiro, J. (2005). Histología básic texto y atlas $(+C D-R O M)$. (ELSEVIER MASSON, Ed.).
Kreyling, W. G., Semmler, M., Erbe, F., Mayer, P., Takenaka, S., Schulz, H., \& Ziesenis, A. (2011). Translocation of ultrafine insoluble iridium particles from extrapulmonary organs is size dependent but very low. Journal of Toxicology and Environmental Health, Part A: Current Issues, (March 2012), 1513-1530.

Paur, H. R., Cassee, F. R., Teeguarden, J., Fissan, H., Diabate, S., Aufderheide, M., ... Schmid, O. (2011). In-vitro cell exposure studies for the assessment of nanoparticle toxicity in the lung-A dialog between aerosol science and biology. Journal of Aerosol Science, 42(10), 668-692.

https://doi.org/10.1016/j.jaerosci.2011.06.005

Perez, L. F., \& Hernandez, L. (2006). Determinación De Metales Pesados En Particulas Respirables E Identificación De Fuentes De Emision, a Partir De Un Muestreo Atmosferico En La Localidad De Puente Aranda En La Ciudad De Bogotá. Universidad de La Salle. Retrieved from https://ciencia.lasalle.edu.co/cgi/viewcontent.cg $i$ ? article $=1672 \&$ context $=$ ing_ambiental_sanitari a

Querol, X. (2008). Calidad del aire, partículas en suspensión y metales. Revista Española de Salud Pública, 82(5), 447-453. https://doi.org/10.1590/S1135-

57272008000500001

Rosell Farràs, M. G., \& Pujol Senovilla, L. (2008). NTP 797 Riesgos asociados a la nanotecnología. Instituto Nacional de Seguridad e Higiene En El Trabajo, 1-6. Retrieved from http://www.fan.org.ar/wp-

content/uploads/2014/05/Riesgos-asociadosnanotecnologia.pdf

Secretaría de Medio Ambiente y Recursos Naturales. (2011). Cuarto almanaque de datos y tendencias de la calidad del aire en 20 ciudades mexicanas (2000-2009). In Zona Metropolitana de Guadalajara, Jal. (Primera, pp. 117-127). México. Retrieved from http://www2.inecc.gob.mx/publicaciones/libros/ 652/guadalajara.pdf

United States Environmental Protection Agency. (2015). Understanding Particle Pollution. Retrieved from https://airnow.gov/index.cfm?action=aqibasics. particle 
United States Environmental Protection Agency. (2016). Particulate Matter (PM) Pollution. Retrieved from https://www.epa.gov/pmpollution

Utell, M. J. (2002). the Urban Air: To the Respiratory Tract- And Beyond? Environmental Health Perspectives, 110(8), 2001-2002. Retrieved from http://www.ncbi.nlm.nih.gov/pmc/articles/PMC 1240959/pdf/ehp0110-a00440.pdf

Yu, L. E., Lanry Yung, L.-Y., Ong, C.-N., Tan, Y.-L., Suresh Balasubramaniam, K., Hartono, D., ... Ong, W.-Y. (2007). Translocation and effects of gold nanoparticles after inhalation exposure in rats. Nanotoxicology, 1(3), 235-242. https://doi.org/10.1080/17435390701763108 